\title{
Study of Two-Metal (Cu-Ag) Micro Heat Pipe of Square Cross Section Using Different Liquids of Low Boiling Point
}

\author{
KMN S. Iqbal", M. A. R. Akhanda \\ Department of Mechanical and Chemical Engineering, Islamic University of Technology, OIC, Dhaka, Bangladesh \\ *Corresponding author: kiqbal@iubat.edu
}

Received June 11, 2014; Revised July 07, 2014; Accepted July 22, 2014

\begin{abstract}
The efficiency-to-size ratio of the electronic machines has been increasing rapidly while leaving the electronics highly thermally stressed. In an attempt to solve the overheating issue, a comparative study is conducted between a two-metal $(\mathrm{Cu}-\mathrm{Ag})$ micro heat pipe and the contemporary single-metal one $(\mathrm{Cu})$ which is currently being installed in the electronic equipment. Thermal effects of a two-metal square cross section micro heat pipe (MHP) at steady state are experimentally investigated. It is a $150 \mathrm{~mm}$ long square hollow tube having each side of $3.6 \mathrm{~mm}$ and thickness of $0.3 \mathrm{~mm}$ which holds a $3.0 \mathrm{~mm}$ hollow space axially. The evaporator and condenser sections are made of pure copper and silver respectively while the adiabatic section is made of both copper and silver. Water and three low boiling point liquids - ethanol, methanol and iso-propanol - are used as working fluids. In view of the usage of the actual equipment, tests are conducted by placing the heat pipe at three different inclinations of $0^{\circ}, 45^{\circ}$ and $90^{\circ}$. To provide heat flux, an electric heater-coil has been wrapped around the evaporator simulating the heat-generation within an actual device, and simultaneously the condenser section is directly cooled by ambient water in an annular space. Internal fluid-flow is considered to be one dimensional. Ten K-type thermocouples are installed at different locations - five of them are to measure the temperatures of internal fluid and five are used to measure the surface temperatures of the tube. Temperatures are monitored by digital electronic thermometers. Unlike in the single-metal micro heat pipe (SMMHP), it is found that the super heater effect in the evaporator of TMMHP simplify the complex two-phase flow into a superheated vapor. Thus, it increases TMMHP's heat transfer capability multiple times higher than that of SMMHP.
\end{abstract}

Keywords: micro heat pipe, two-metal micro heat pipe, TMMHP, square cross section, hydraulic diameter, steady state, one dimensional flow, inclination

Cite This Article: KMN S. Iqbal, and M. A. R. Akhanda, "Study of Two-Metal (Cu-Ag) Micro Heat Pipe of Square Cross Section Using Different Liquids of Low Boiling Point." American Journal of Mechanical Engineering, vol. 2, no. 3 (2014): 82-92. doi: 10.12691/ajme-2-3-5.

\section{Introduction}

Micro heat pipe (MHP) is a heat transferring device based on the phase change phenomenon of fluid contained in it. Before filling with the fluid, the container must be vacuumed to below the atmospheric pressure. MHP is considerably of small diameter, usually not over $3.0 \mathrm{~mm}$. The micro heat pipe receives heat at one end to vaporize the fluid which is evaporator, and then travels through the next section losing no heat called adiabatic section, and terminally the condenser part from where the carried away heat dissipates to the atmosphere. Usually, micro heat pipe is made with good heat conducting metal, i.e. copper, stainless steel, nickel etc. Depending on the operating temperature range, selected working fluids may be water or hydrocarbon compounds or it can be cesium, bismuth, sodium, lithium etc. Fluids of low boiling point (LBP) indicate here the fluids that have boiling points below the water at atmospheric pressure. A wick is shaped accordingly, and inserted within the heat pipe spanning end to end to let the condensate crawl back to the evaporator by capillary action. The wick can be made of stainless steel mesh, sintered metal powder, fiber, wire braid etc. In a micro heat pipe, the presence of sharp or non circular edges, and in other case, radially etched micro grooved inner wall of the MHP are also replacing wick that provides the capillary service. Comparing with solid metal, heat transport ability of a heat pipe of same geometry is found to be many times high at a small temperature difference. MHP's applications are widely endorsed in cooling microelectronics, nuclear reactors as far as in space satellites. Globally many researchers have been engaged in improving the MHP concepts for the last several decades; however, few of their works are cited bellow.

Study on heat pipe has been in practice since 1942 when R. S. Gaugler of General Motors, USA proposed [1] However, heat pipe did not receive a target oriented attention until 1963 when Grover et al. [2] directed the 
heat pipe's condensate-returning mechanism from its confined gravitation-fed state to the simple capillary-force action of wick structure inserted in it. By the U.S. government funding, between 1964 and 1966, RCA was the first corporation to undertake research and development of heat pipes for commercial applications [3]. Starting in the 1980s Sony began incorporating heat pipes into the cooling schemes for some of its commercial electronic products instead of the more traditional finned heat sink with and without forced convection. But, it was twenty years later in 1984 when T. P. Cotter first introduced the idea of "micro" heat pipes [1]. Sreenivasa et al. [4] determined the optimum fill ratio in miniature heat pipe which indicates the same performance as the evaporator section was half filled rather than filling in full. Akhanda et al. [5] tested an air cooled condenser to investigate the thermal performance of MHPs charged with different fluids and oriented a different inclinations. Sakib Lutful Mahmood [6] at Islamic University of Technology (IUT), OIC has performed tests on different cross sections of MHP of the same hydraulic diameter charged with water at different inclinations. It was found that the best heat transfer coefficient at the circular cross section was at an angle of $90^{\circ}$. Further observation was made as the thermal resistance of micro heat pipe increases with increasing of flatness ratio and its heat transfer coefficient decreases also with increasing of flatness ratio. Finally, Sakib developed an empirical equation from the experimental data and correlated all his findings which showed $\pm 7 \%$ nearness with the developed equation. Moon [10] used a miniature heat pipe (MHP) which was squeezed in the Notebook PC to cool which may be heated up to $100^{\circ} \mathrm{C}$. From the output of the experiment using MHP with woven wire wicks was found to be quiet viable candidate for a stable cooling unit of Notebook P. C. Babin et al. [11] developed the model that analyzes the heat transport behavior of micro-heat pipe, and presented the model of micro-heat pipe based on the analysis by Chi [12] in a steady-state operation. Longtin et al. [13] presented the improved prediction results, considering partially the shear stress in liquid-vapor interface of groove in a micro heat pipe. Swanson and Peterson [14] analyzed thermo-dynamically the heat transport phenomena in the liquid-vapor interface of heat pipe, and $\mathrm{Wu}$ and Peterson [15] studied the thermal performance of micro-heat pipe in an unsteady state. Le Berre et al. [16] studied experimentally the performance of a micro heat pipe array for various filling charges under various experimental conditions. The results showed that the performance of the micro heat pipe array is favored by decreasing the input heat flux or increasing the coolant temperature. Kole and Dey [17] investigated thermal performances using $\mathrm{Cu}$-distilled water nano-fluid which enhanced thermal conductivity by $15 \%$ at $30^{\circ} \mathrm{C}$. Chiang et al. [18] developed a magnetic-nanofluid (MNF) heat pipe (MNFHP) with magnetically enhanced thermal properties. The results showed that an optimal thermal conductivity exists in the applied field of 200 Oe.

Throughout this survey, it has been found that only a single metal or bimetal alloy has been used to manufacture the heat pipes including its varieties of isometric geometry. In these cases, heat transfers occur only at constant heat conductivity at both ends of MHP for being it a single metal or an alloy. No individual or company has been found to have attempted on doing investigation on a variable heat conductivity micro heat pipe. Thus, a twometal micro heat pipe (TMMHP) made with two different metals (i.e. $\mathrm{Cu}$ and $\mathrm{Ag}$ ) of closer heat conductivity (i.e. $398 \mathrm{~W} / \mathrm{m}-\mathrm{K}$ for copper and $429 \mathrm{~W} / \mathrm{m}-\mathrm{K}$ for silver) for variable heat conductivity has been selected by the author Iqbal [8] in his doctoral thesis. Out of four TMMHP cross sections, Iqbal and Akhanda [9] found the triangular one enhances the heat transfer coefficient by two and a half times from that one produced by SMMHP [6]. Moreover, because of its geometry, the pressure gradient of the working fluid will also be variable in the respected TMMHP sub-sections. A series of heat inputs ranging from $2 \mathrm{~W}$ to $16 \mathrm{~W}$ have been supplied to the evaporator keeping the MHP at $0^{\circ}$ to study the heat transfer behavior of pure water along with ethanol, methanol and isopropanol. Then it was reexamined at $45^{\circ}$ and $90^{\circ}$ positions (evaporator uphill) while the condenser was being cooled by ambient water at a constant flow-rate of $400 \mathrm{ml} / \mathrm{min}$. At the end, the fluid temperatures within the TMMHP as well as the surface temperature at designated locations at steady state have been recorded to compare with other researchers' experimental data. To confirm the reproducibility of the data, the experiments were repeated and found to be on the same trend line.

\section{Experimental Setup}

The experimental set up is essentially consisting of a TMMHP, a storage tank, a measuring cup, a power source and a digital thermometer. The schematic diagram of the experimental set up is shown in Figure1. Table 1 provides the physical dimensions of the TMMHP. The TMMHP used in this experiment is a $150 \mathrm{~mm}$ x $3.6 \mathrm{~mm}$ square copper and the other half with pure silver. The copper-end is the evaporator section while the silver-end is the condenser. The lengths of the evaporator and adiabatic sections are of equal length of $45 \mathrm{~mm}$ each and the rest 60 $\mathrm{mm}$ is the condenser section. Thus, the evaporator and condenser are fully covered with copper and silver respectively while the adiabatic section is with both metals. The evaporator side is then welded to seal.

Table 1. Physical Dimensions of TMMHP (Square)

\begin{tabular}{|l|c|c|}
\hline \multicolumn{1}{|c|}{ Specifications } & Dimensions & Materials \\
\hline Heat pipe total length & $150 \mathrm{~mm}$ & Copper \& Silver \\
\hline Evaporator section length & $45 \mathrm{~mm}$ & Copper \\
\hline Adiabatic section length & $45 \mathrm{~mm}$ & Copper \& Silver \\
\hline Condenser section length & $60 \mathrm{~mm}$ & Silver \\
\hline Heat pipe each side length & $3.6 \mathrm{~mm}$ & \\
\hline Heat pipe profile height & $4.2 \mathrm{~mm}$ & \\
\hline Heat pipe wall thickness & $0.3 \mathrm{~mm}$ & \\
\hline Mesh number of wick & 7 holes per cm & \\
\hline Wick thickness & $0.3 \mathrm{~mm}$ & \\
\hline Working fluid & $\begin{array}{c}\text { Methanol, Ethanol, } \\
\text { Iso-propanol and } \\
\text { /Water }\end{array}$ & \\
\hline $\begin{array}{l}\text { No. of surrounding heater in } \\
\text { the evaporator section }\end{array}$ & \begin{tabular}{c} 
1 [ SGW36] \\
\hline Insulating material
\end{tabular} & \\
\hline
\end{tabular}




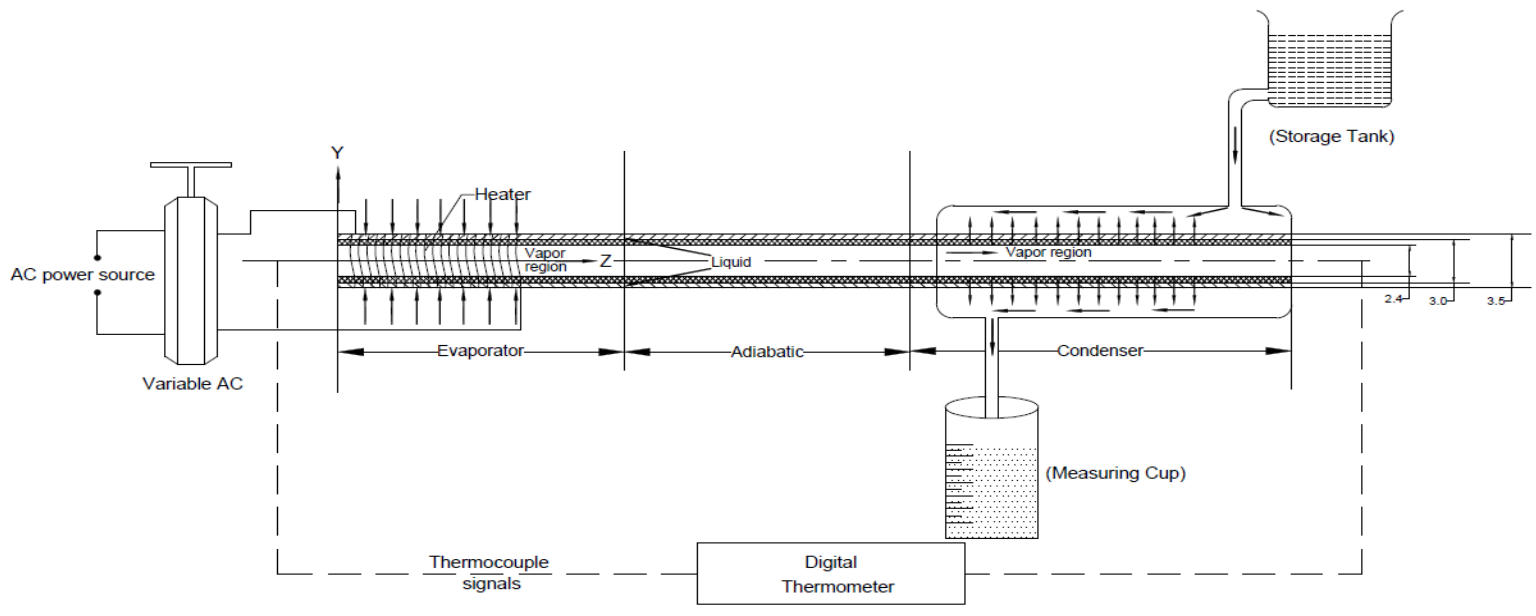

Figure 1. Schematic diagram of the experimental setup at $0^{\circ}$ inclination

As for wick, a steel mesh of $0.3 \mathrm{~mm}$ thickness with the equal length of TMMHP has been wrapped around a mandrel and inserted into the tube so that the wick radially press fit the inner wall of the tube. Five $1.1 \mathrm{~mm}$ holes are drilled according to the Figure 2. Five copper constantan (K-type) thermocouples have been inserted to reach the vapor core and brazed with silver to know the internal working fluid's state. Then another five thermocouples have been attached right beside the holes by quick fixing adhesive to measure the surface temperatures at those locations. The condenser-end of the heat pipe is then plugged into one end of a capillary tube while the other end is attached with a vacuum pump. When pressure within the heat pipe goes well below the atmospheric pressure, and then is locked for a couple of minutes to reconfirm its air freeness. Then a pinch- clip is used to choke the capillary tube near the junction, and a slim syringe (Dispovan, $1 \mathrm{ml}$ ) filled with $0.55 \mathrm{ml}$ of distilled water, which is $100 \%$ (Fill Ratio) of the empty space of the evaporator, is injected into the capillary tube. Actually, the water is sucked into the capillary tube spontaneously because of having lower than atmospheric pressure within the tube. After filling, the condenser-end of the TMMHP is now pinched and sealed by brazing. At the evaporator, a fire and electric shock proof tape has been laid around and then SGW36 electric heater wire has been coiled out at a closer pace possible without clinging to each other. To avoid the dispersion of heat produced by the heater in view to keep the heat input value significantly unaltered, the coil was insulated by the asbestos rope by many folds and was extended up to the end of adiabatic section. Finally, another strip of insulating tape was wrapped around to avoid getting soaked by the splash of water. Now the condenser-end of the TMMHP is wrapped up with cotton and inserted into a plastic container which has two outlets. Then the outlets are connected with flexible water tube-upper one is fitted with the valve of the coolant (water) reservoir and the lower one is dipped into an empty measuring bucket to collect the used coolant.

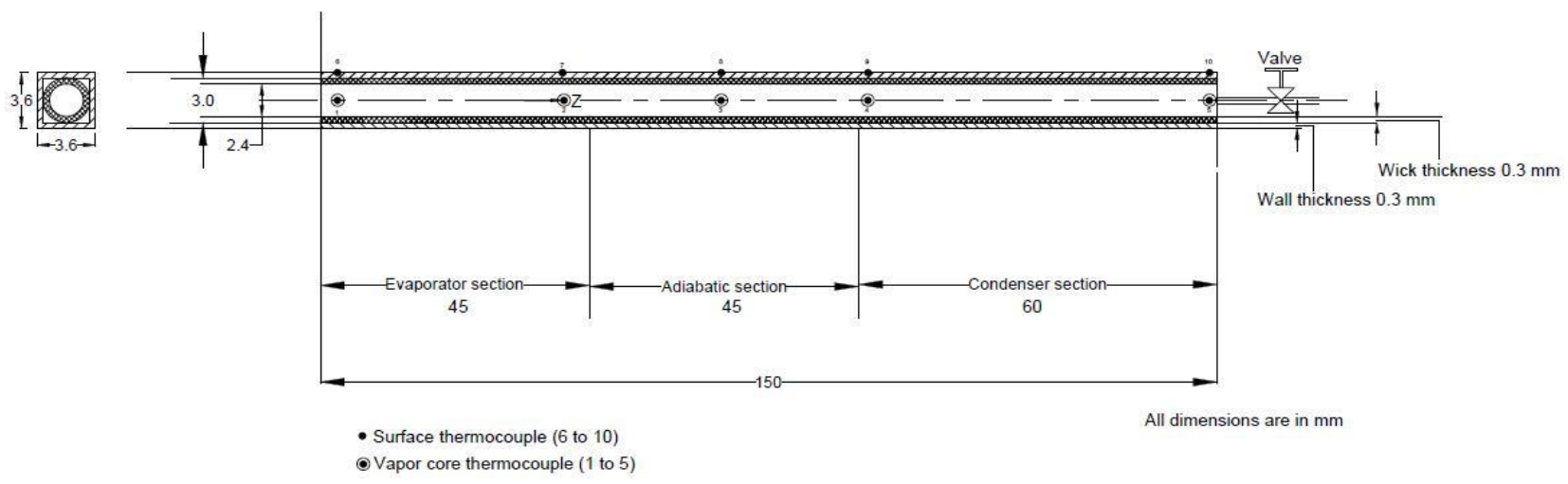

Figure 2. Positions of thermocouples along the TMMHP

The whole setup is then mounted on a rig which is placed on a wooden table. All the thermocouples have been calibrated and found with \pm 0.1 degree Celsius variations. Then the thermocouples have been connected with a digital thermometer through a selector switch. The coolant reservoir is filled with the supplied water which is placed above the level of TMMHP. To produce the variable heat input for the heat pipe, a Variac has been introduced, which is then monitored by one ammeter and one precision voltmeter to record the current and voltage simultaneously.

\section{Test Procedures}

At first the coolant flow is opened to run through the condenser end to ensure the condenser jacket is soaked and fully immersed with water. Then the Variac is connected with the AC power source to produce controlled heat by the heater. The power range is chosen from $2 \mathrm{~W}$ to $16 \mathrm{~W}$ producing heat flux ranging $3.1 \mathrm{~kW} / \mathrm{m}^{2}$ to $24.7 \mathrm{~kW} / \mathrm{m}^{2}$ simulating the generated heat in a laptop 
computer processor and similar electronic equipment [6]. It can be noted, before wrapping the heater coil, its red-hot power limit is checked and found to be $24 \mathrm{~W}$. Thus, the upper limit of $16 \mathrm{~W}$ is quite safe for the experimental purposes. Initially, the TMMHP is inclined at $0^{\circ}$ (horizontally), and the time and temperature at the evaporator are recorded until the system reaches steady state. The experiment is continued by keeping the setup at $45^{\circ}$ and $90^{\circ}$ with evaporator uphill position. To attain steady state, a minimum coolant flow rate of $400 \mathrm{ml} / \mathrm{min}$ or $70 \mathrm{ml} / \mathrm{s}$ has been found to be reasonable to find the used coolant temperature equal to ambient. Although the initial steady-state for $2 \mathrm{~W}$ is achieved not until ten minutes; however, the subsequent steady-states takes only third of the time or less than three minutes.

\section{Results and Discussions}

Using gathered data in this investigation various curves are plotted as shown from Fig. 3 to Fig. 21. Figure 3 shows time required for reaching steady state temperature for different working fluids. It was found that ethanol took the least time out of four while the other three delayed approximately the same period of time. Ethanol and isopropanol advances parallel in terms of temperature rise as well as attaining steady-state condition-this may occur because of their proximity of boiling points (BP). On the other hand, methanol and water took longer to reach but at a higher temperature range than the other two. It is observable that although the methanol's boiling is low, still it took the same time period of water. This indicates the earlier boiling and condensation of methanol than other fluids, which becomes chaotic within the narrow space of the micro heat pipe. Consequently, methanol took longer period of time to reach thermal equilibrium thus to attend steady state than that of others. On the other hand, water took the same time but at a higher temperature than the other three. Therefore, the heat capacity of a fluid not only depends on its thermophysical properties (i.e. density, SG etc.) but also on its chemical bonding (i.e. hydrogen bonding for water).

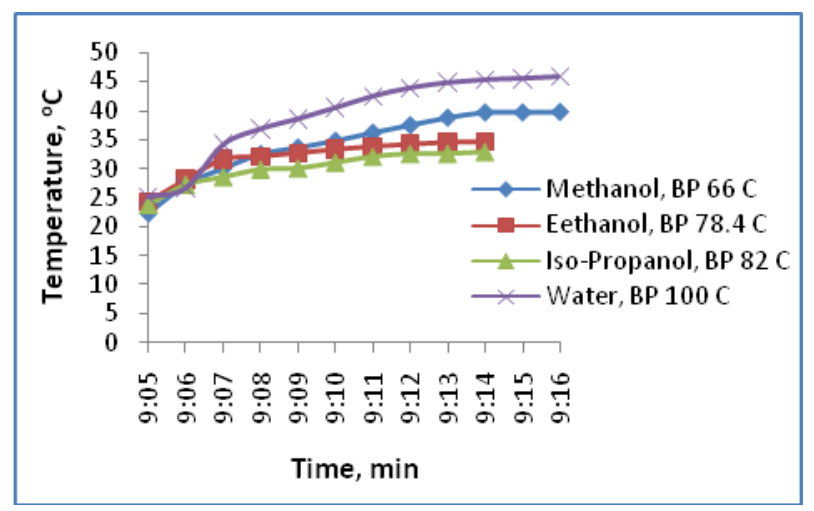

Figure 3. Time required for reaching steady-state of different fluids

The trends of temperature rises (meter reading minus the ambient, $25^{\circ} \mathrm{C}$ ) at the evaporator section for using different fluids in TMMHP are shown in Figure 4. Other than water, all three are nonlinear. This may happen because of the three are organic compounds and have similar chemical bonding, and the water as an inorganic compound is made up from hydrogen and oxygen's covalent bond. Again it supports the phenomenon that the heat capacity of a fluid is not simply based on thermophysical property (i.e. density, boiling point, SG etc.) rather mainly on its bonding.

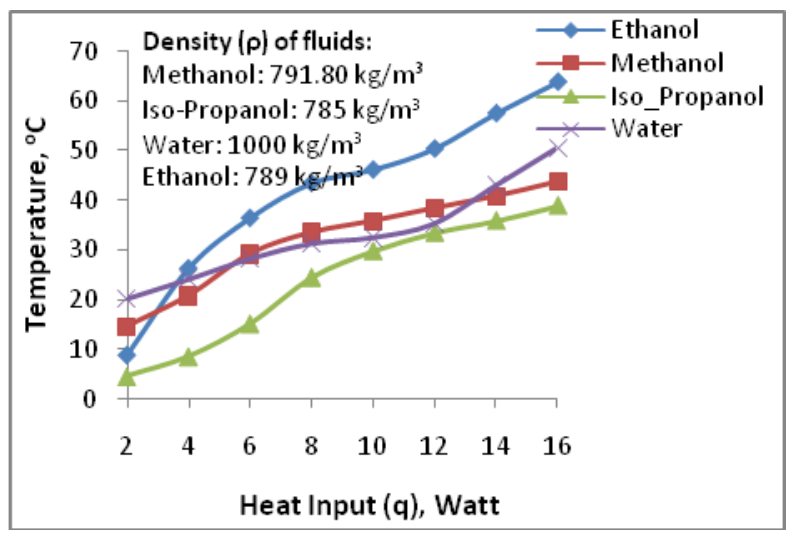

Figure 4. Rise of fluid temp. vs. heat input at the evaporator

\subsection{Evaporator of TMMHP as a Super Heater}

Distributions of temperatures along the length of the TMMHP for different working fluids, for different heat inputs, and also for different inclinations are shown from Figure 5 (a) to 12 (b). It was observed from these figures that in each case of fluid used in TMMHP, there was a temperature rise in the evaporator from $T_{1}$ to $T_{2}$. Annamalai A. S. et al. [7] has reasoned that "In the evaporator zone heat is supplied by an electric coil and the coil surface area density is very high in the middle of the evaporator portion and hence the temperature of the vapor in the middle of the evaporator is high". Authors here disagree with Annamalai that there should be no reason to windup the heater coil densely in the middle of the evaporator rather wrapping must be uniformly done so the produced heat flux remains constant throughout the evaporator. Based on this work and the work of Sakib [6] and Sreenivasa [4], the working fluid should be filled only equal to or less than the empty space (vapor core) of the evaporator of the heat pipe. However, a lot more space in the heat pipe is still vacant to travel during operation. Soon after the MHP goes on operation, boiling starts at the beginning of the heat pipe - part of the fluid evaporatesthat leaves a significant room empty within the evaporator which is fully wrapped up by the heater coil. Therefore, when the saturated vapor advances, it continuously receives heat from that part of heater to become superheated, and then it enters the adiabatic section. That's why we notice the temperature rise at point $T_{2}$, hence this end of the evaporator act as a super heater.

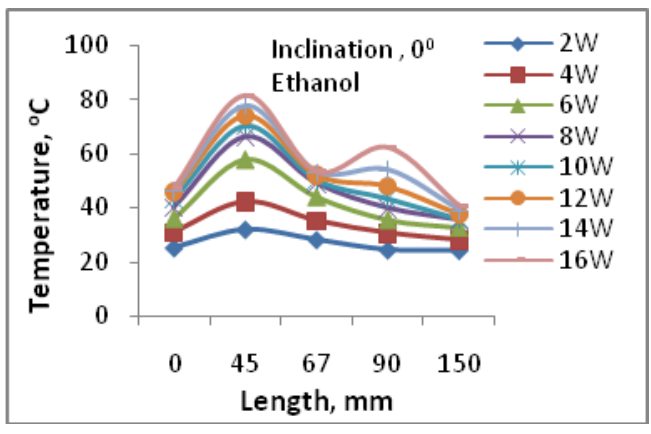

Figure 5 (a). Fluid temp. distribution along the TMMHP 


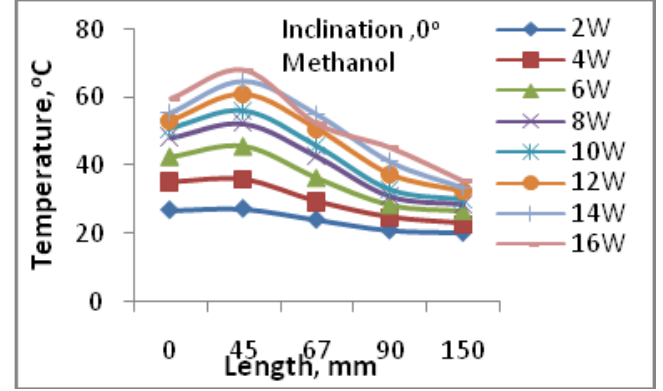

Figure 5 (b). Fluid temp. distribution along the TMMHP

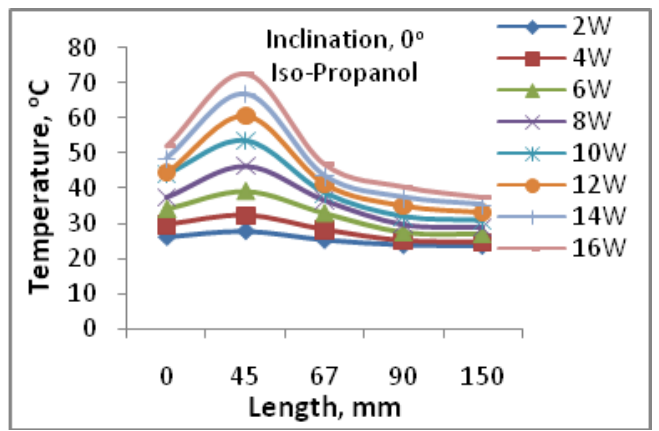

Figure 5 (c). Fluid temp. distribution along the TMMHP

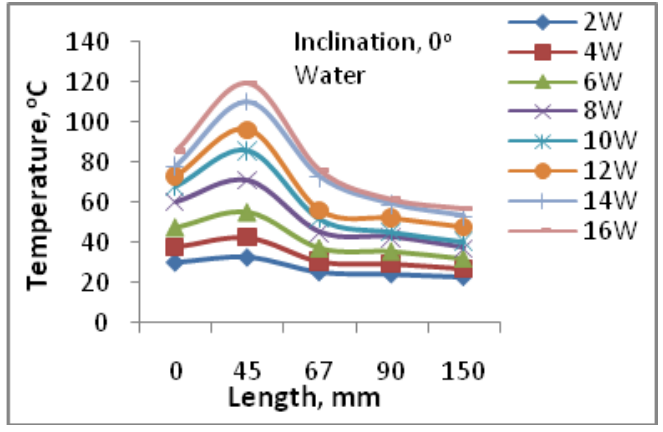

Figure 5 (d). Fluid temp. distribution along the TMMHP

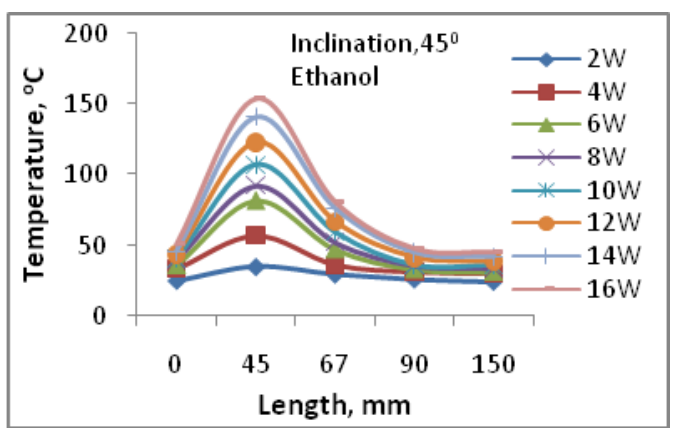

Figure 6 (a). Fluid temp. distribution along the TMMHP

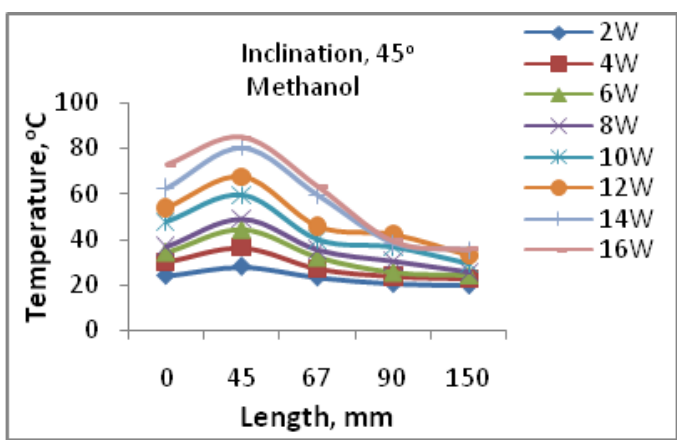

Figure 6 (b). Fluid temp. distribution along the TMMHP

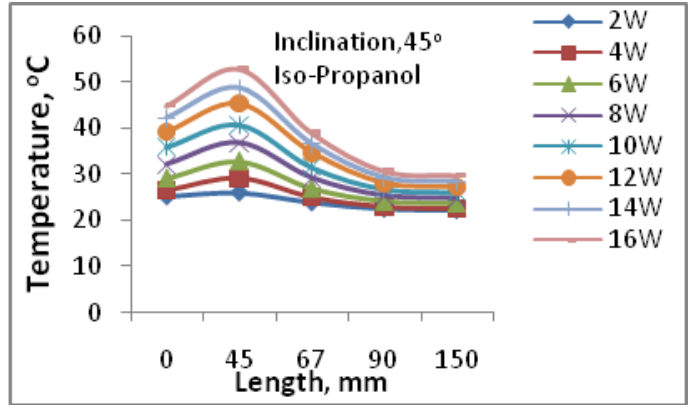

Figure 6 (c). Fluid temp. distribution along the TMMHP

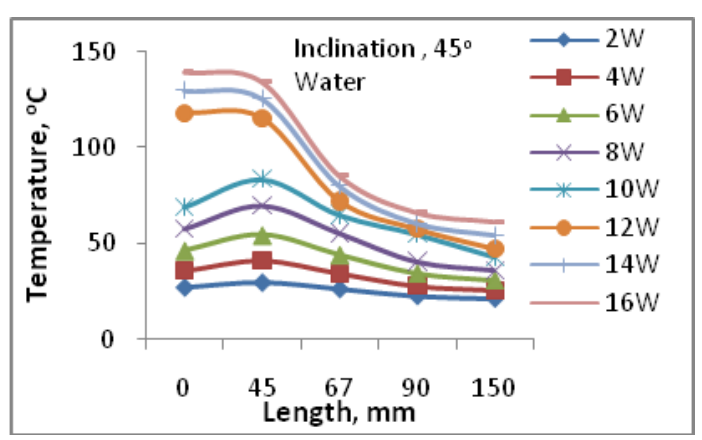

Figure 6 (d). Fluid temp. distribution along the TMMHP

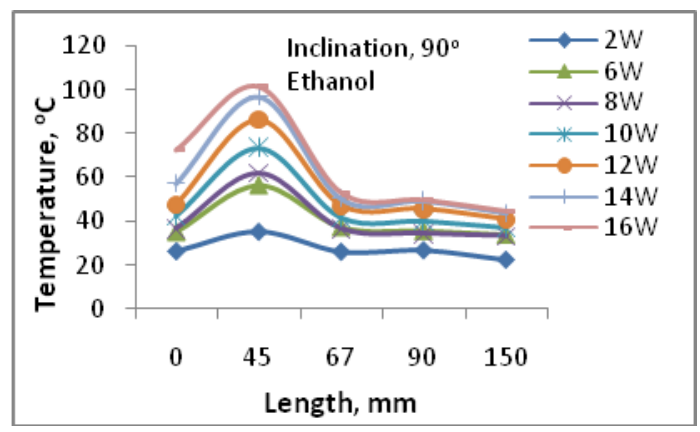

Figure 7 (a). Fluid temp. distribution along the TMMHP

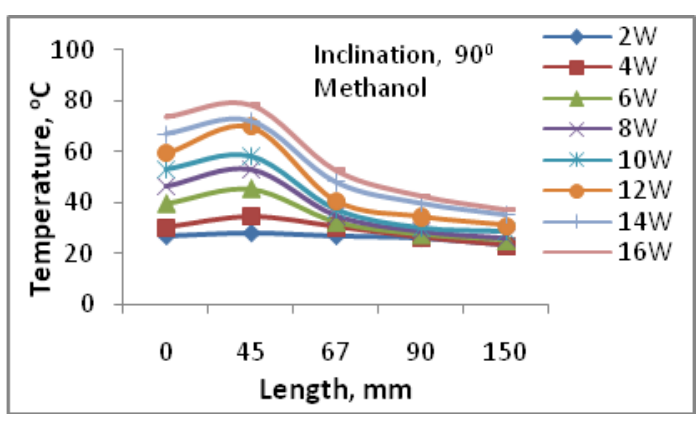

Figure 7 (b). Fluid temp. distribution along the TMMHP

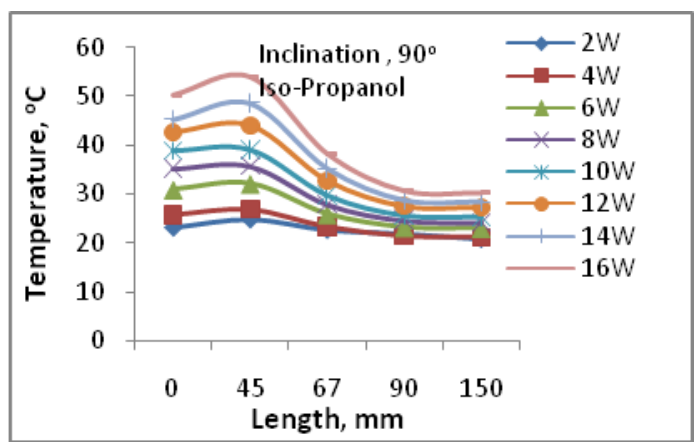

Figure 7 (c). Fluid temp. distribution along the TMMHP 


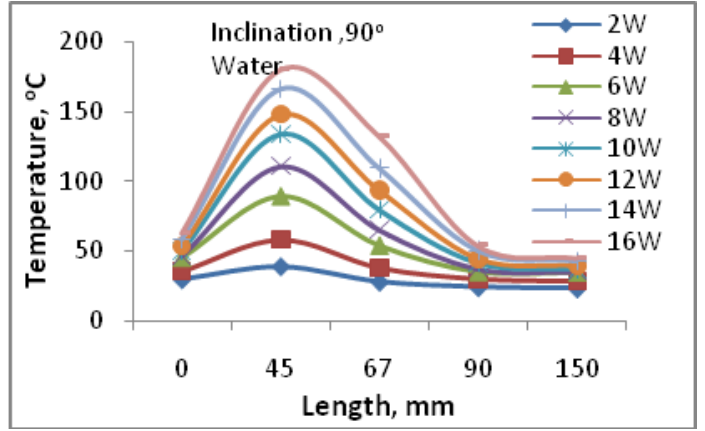

Figure 7 (d). Fluid temp. distribution along the TMMHP

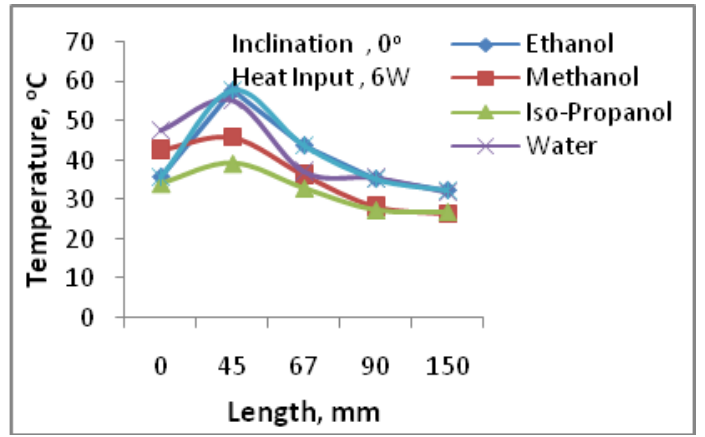

Figure 8 (a). Temp. distribn. along TMMHP for diff. fluids

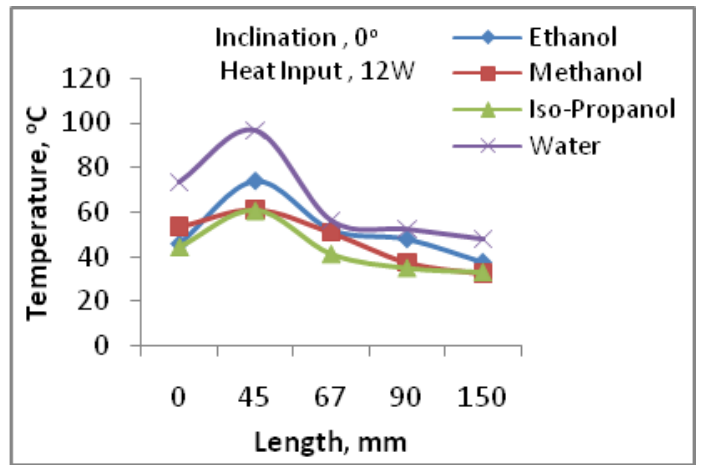

Figure 8 (b). Temp. distribn. along TMMHP at diff. fluids

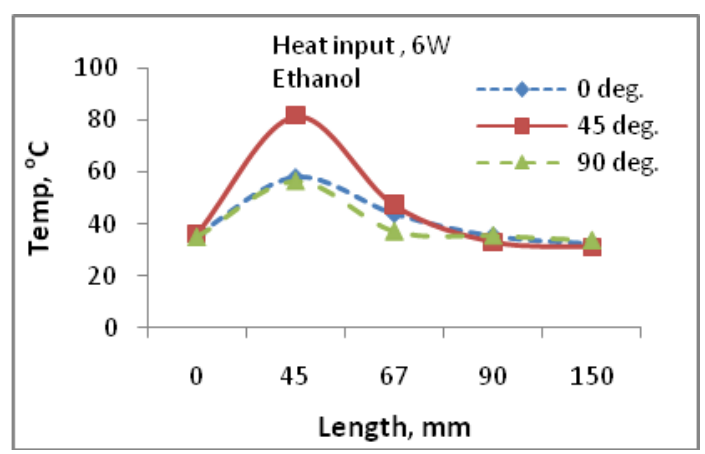

Figure 9 (a). Temp. distribn. along TMMHP at diff. inclns

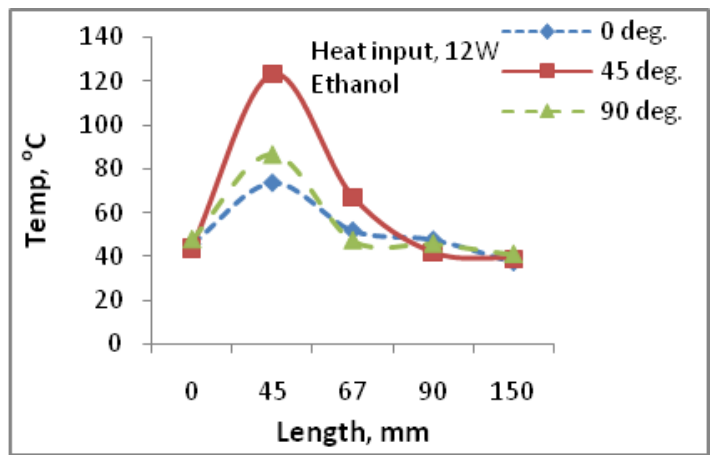

Figure 9 (b). Temp. distribn. along TMMHP at diff. inclns

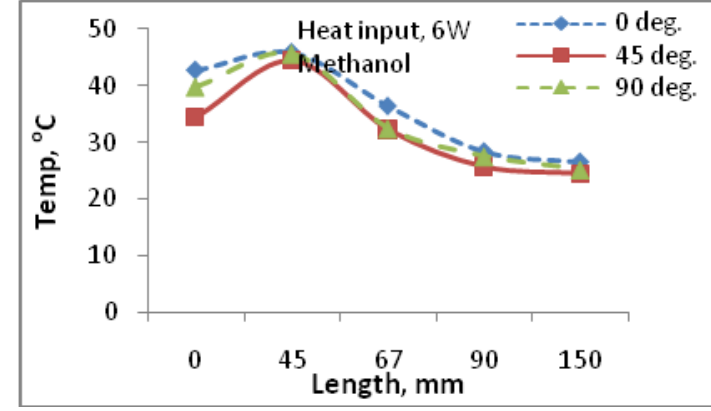

Figure 10 (a). Temp. distribn. along TMMHP at diff. inclns

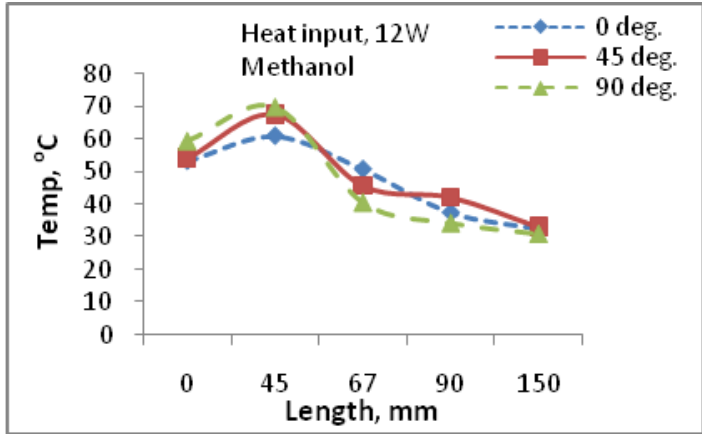

Figure 10 (b). Temp. distribn. along TMMHP at diff. inclns

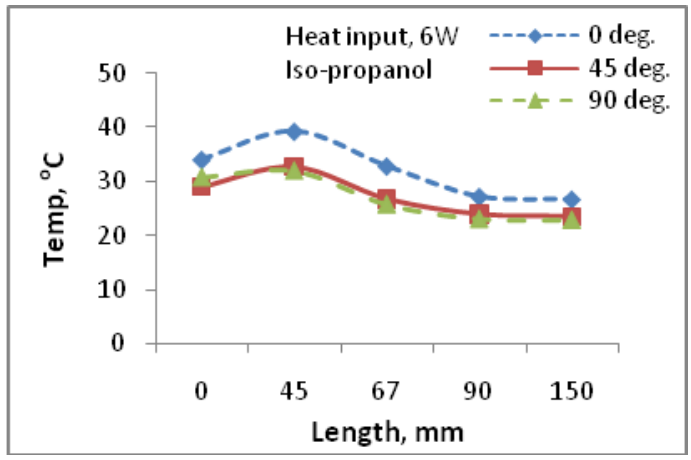

Figure 11 (a). Temp. distribn. along TMMHP at diff. inclns

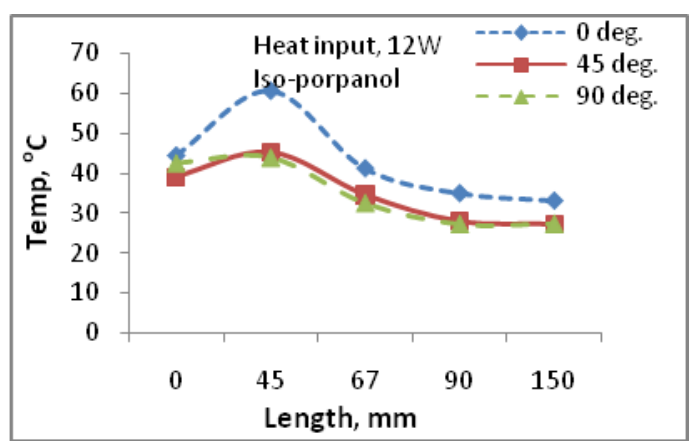

Figure 11 (b). Temp. distribn. along TMMHP at diff. inclns

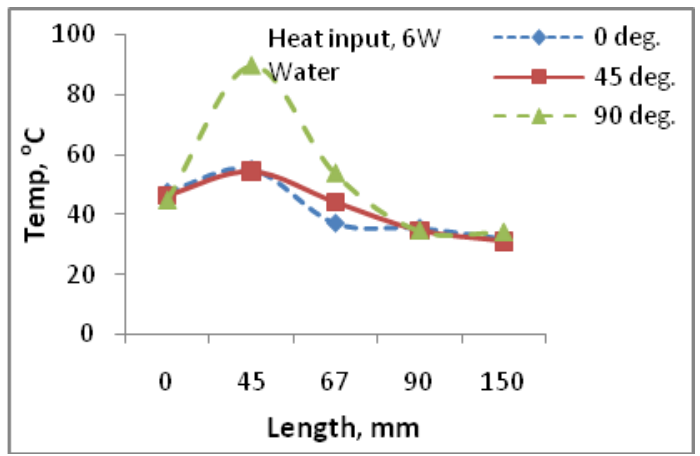

Figure 12 (a). Temp. distribn. along TMMHP at diff. inclns 


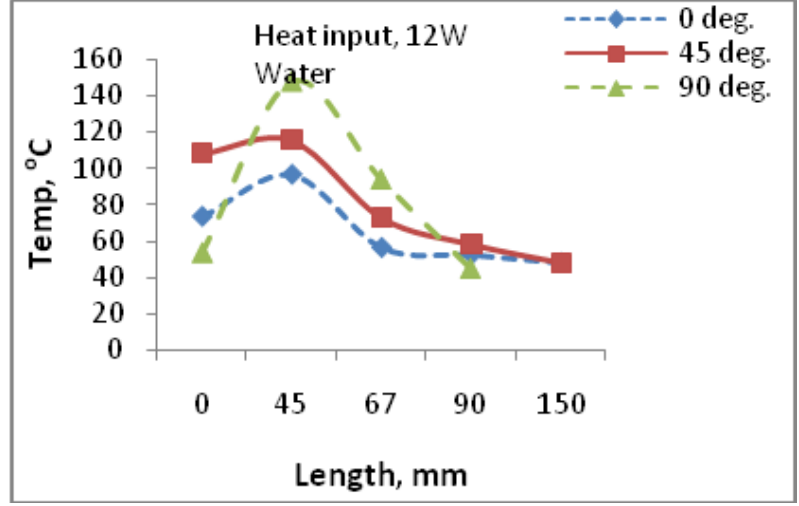

Figure 12 (b). Temp. distribn. along TMMHP at diff. inclns

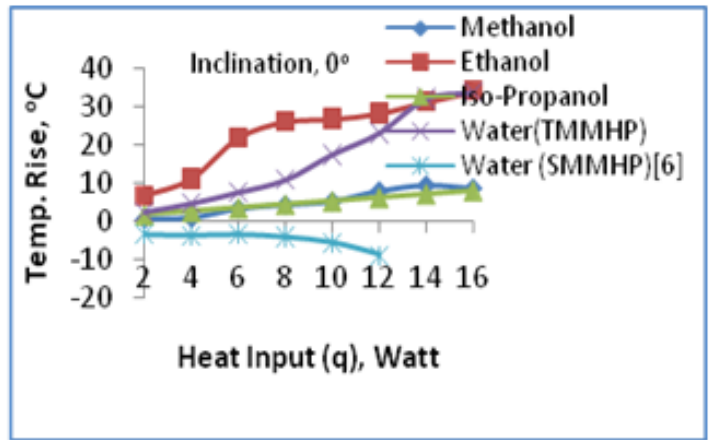

(a)
Regarding the rise of temperature in the evaporator, a comparative relationship between the fluids in the TMMHP and in the SMMHP [6] is shown in Figure 13 (ac). The trend for temperature rise for all the hydrocarbons is quite similar throughout the heat pipe. However, the water showed different values in all three inclinations. It becomes obvious that the orientation of the TMMHP plays an important role in superheating quality of the fluids. On the other hand, in the case of SMMHP [6,7] the trend is always negative.

Figure 14 indicates that water was condensed within the highest temperature band because of the highest specific heat $\left(\mathrm{C}_{\mathrm{p}}\right)$ while the iso-propanol became the lowest. However, the sequence of the condensation of the fluids remains the same in all three different inclinations.

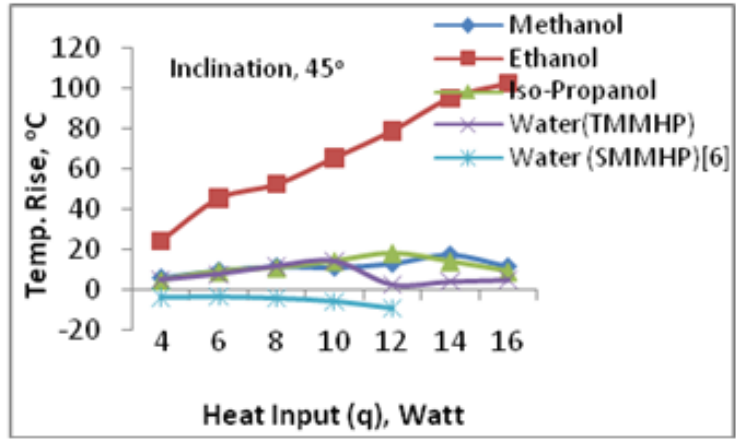

(b)

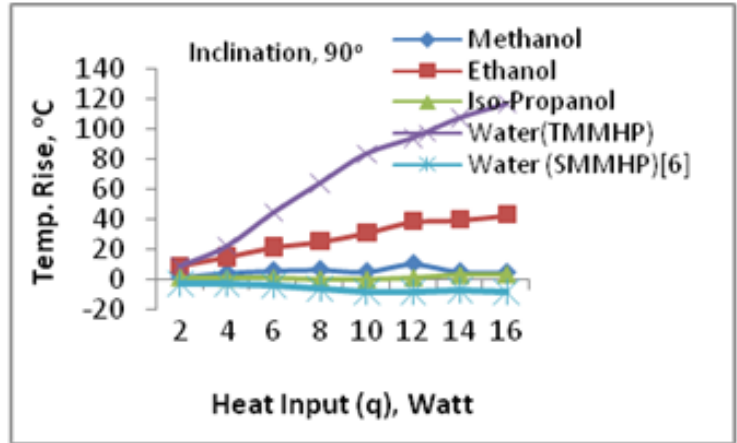

(c)

Figure 13(a-c). Comparison of temp. rise $\left(\mathrm{T}_{2}-\mathrm{T}_{1}\right)$ of TMMHP with SMMHP [6] of diff. fluids at diff. inclinations

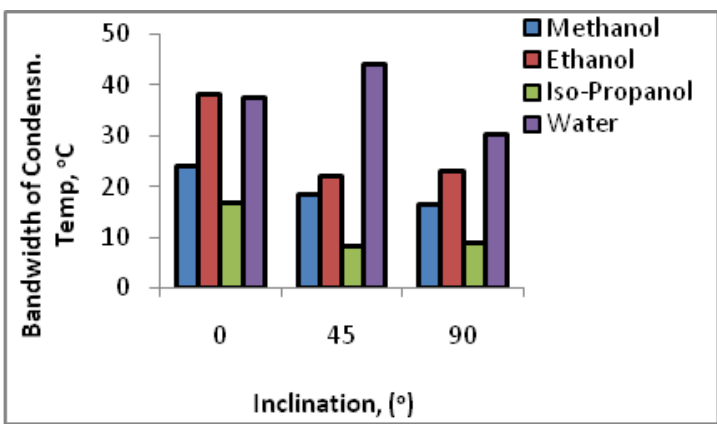

Figure 14. Band-width of condensn. temp. $\left(\mathrm{T}_{4,16 \mathrm{~W}}-\mathrm{T}_{4,2 \mathrm{~W}}\right)$ of diff.fluids for diff. heat inputs applied to TMMHP at diff.inclins

At $90^{\circ}$ inclination, the values were significantly low because of possible "dried out" situation. Capillary action of the water and hydro-carbons are quite different. As a result, the values of the three hydrocarbons are closely placed while the value of water is far away from them. Thus it is proved again that the heat capacity of a liquid is not only depended on its physical property but also on its chemical property (i.e. structural bonding). While being condensed, the internal working fluids were experiencing negative temperature gradient within the condenser as shown in Figure 15. It is noticeable that the sequence of negativity of the fluids within the condenser is just the opposite of that in the evaporator (Fig. 13).

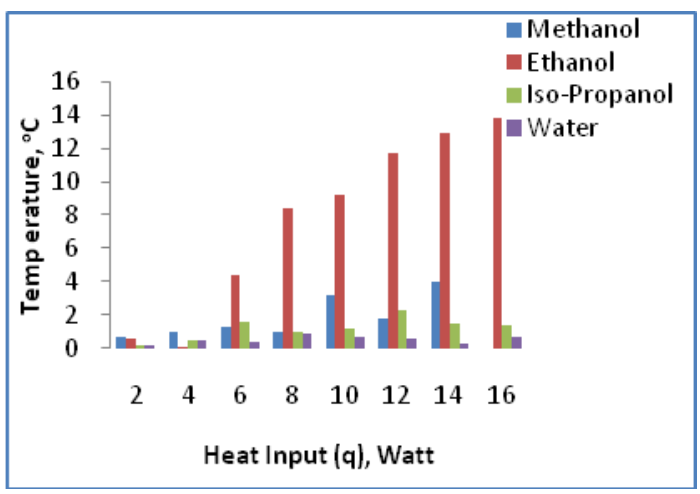

Figure 15. Comparison of condensn. temp. $\left(\mathrm{T}_{5}-\mathrm{T}_{4}\right)$ range of diff. fluids for increasing heat inputs to TMMHP at $0^{\circ}$ 


\subsection{Comparison of $h$ for Water between TMMHP and SMMHP}

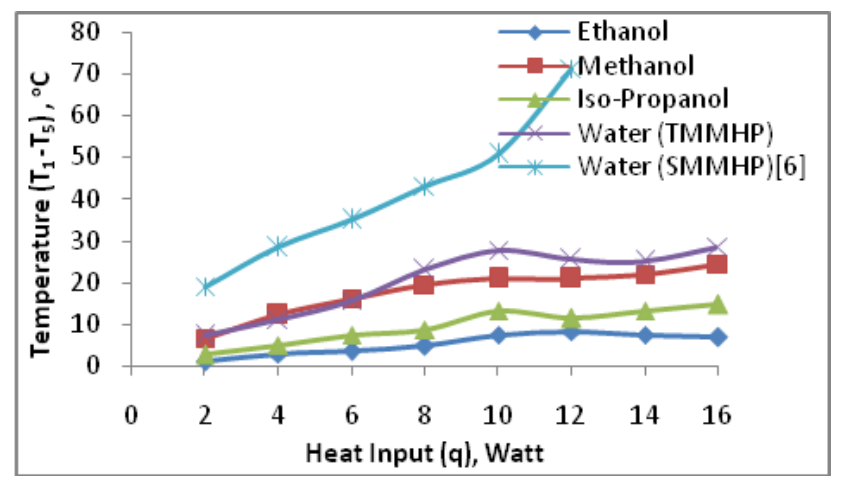

Figure 16. Comparison of terminal temp. diffs. $\left(\mathrm{T}_{1}-\mathrm{T}_{5}\right)$ of TMMHPwith SMMHP [6] at $0^{\circ}$

The efficiency of MHP is highlighted by its heat transfer capability at a lower temperature difference. A comparison between the TMMHP and SMMHP [6] is shown in Figure 16. As it is seen, the terminal temperature difference at TMMHP is only the third or even less than that of at SMMHP. This has become possible because of relatively higher conductivity of silver at the condenser port that accelerates the thermodynamic cycle of the working fluid within the heat pipe. In Figure 17 and $18, h$ values of water at both SMMHP [6] and TMMHP for different inclinations can be compared. The $h$ values at TMMHP are high and sinusoidal throughout the heat input range while the $h$ at SMMHP began with very low values and grows too slow with the increasing heat input. However, the highest value of $h$ was recorded at $90^{\circ}$ for both SMMHP and TMMHP. Therefore, if all the operating and test parameters remain the same at both single and two- metal micro heat pipe, the variability of heat conductivity as well as their designed orientation in TMMHP is considered to be the only initiator for greater $h$.

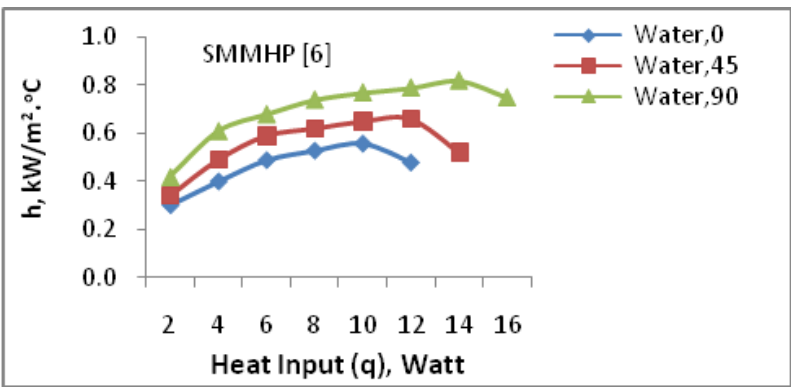

Figure 17. Convec. HT coeffs. of water in SMMHP [6] at diff. inclns

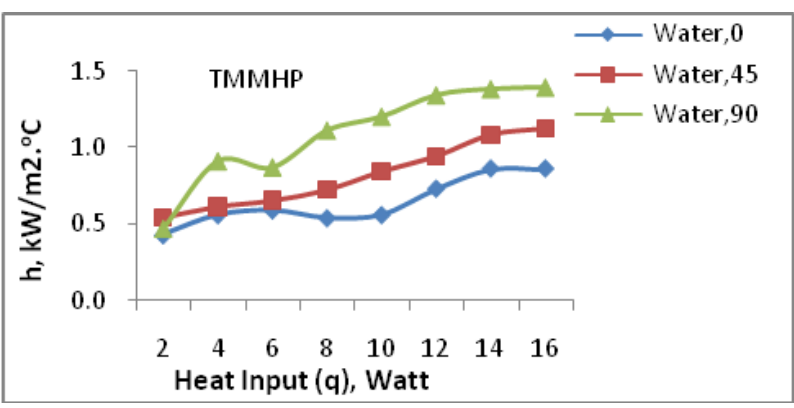

Figure 18. Convec. HT coeffs.of water at TMMHP at diff. inclns

Table 2. Comparison of Thermal Performance between SMMHP [6] and TMMHP

\begin{tabular}{|l|l|l|l|l|}
\hline S1. No. & Parameters & SMMHP [6] & TMMHP & Remarks \\
\hline 1 & Thermal conductivity (k) & Constant & Variable & Rate of heat removal is increased in TMMHP. \\
\hline 2 & $\begin{array}{l}\text { Bandwidth of condensation } \\
\text { temperature (Water, } 0^{\circ} \text { incln.) }\end{array}$ & Small, $3.6^{\circ} \mathrm{C}$ & Large, $36^{\circ} \mathrm{C}$ & $\begin{array}{l}\text { Condensation takes place at higher temp. in } \\
\text { TMMHP than in SMMHP. }\end{array}$ \\
\hline 3 & $\begin{array}{l}\text { Overall temp. difference between two } \\
\text { ends of MHP (Water, } 0^{\circ} \text { incln.) }\end{array}$ & $41.2^{\circ} \mathrm{C}$ & $20.4^{\circ} \mathrm{C}$ & $\begin{array}{l}\text { In TMMHP is much smaller, thus enhances } \\
\text { cyclic order and quick heat removal. }\end{array}$ \\
\hline 4 & Temp. gradient at condenser for water & Negative & Positive & $\begin{array}{l}\text { Positivity at TMMHP improves capillary } \\
\text { action. }\end{array}$ \\
\hline 5 & $\begin{array}{l}\text { Time reqd. to complete cycle, (Water, } \\
0^{\circ} \text { incln.) }\end{array}$ & 2 min & $11 / 2$ min & $\begin{array}{l}\text { Because of thermal vacuum created in } \\
\text { TMMHP. }\end{array}$ \\
\hline 6 & $h / h_{e f f}\left(\right.$ Water, $\left.0^{\circ}\right)$ & 0.94 & 1.22 & $\begin{array}{l}\text { TMMHP value is higher because of lower } \\
\text { terminal temp. diff. that enhances } h .\end{array}$ \\
\hline 7 & $h_{\max }\left(\right.$ Water, $0^{\circ}$ incln.) & $0.46 \mathrm{~kW} / \mathrm{m}^{2} .{ }^{\circ} \mathrm{C}$ & $0.81 \mathrm{~kW} / \mathrm{m}^{2} .{ }^{\circ} \mathrm{C}$ & At TMMHP $h$ reaches almost two times high. \\
\hline 8 & $h$ with respect to increasing Q & $\sim$ uniform & increasing & $\begin{array}{l}\text { Mean value of } h \text { is two times higher at } \\
\text { TMMHP. }\end{array}$ \\
\hline
\end{tabular}

\subsection{Comparison of $\boldsymbol{h}$ for All Fluids between TMMHP and SMMHP}

Figure 19 (a), (b) and (c) show the values of heat transfer coefficient of different fluids at inclinations of $0^{\circ}$, $45^{\circ}$ and $90^{\circ}$. Ethanol possesses the highest ' $h$ ' among all the fluids, and the highest value is attained at inclination $0^{\circ}$. Thus in respect to $h$, ethanol is the most valuable working fluid out of the four for square TMMHP. Since the surface temperature of the TMMHP is depended on the heat input and heat rejection at the evaporator and condenser respectively, such high values of ' $h$ ' become dependent on the internal fluids' overall thermophysical properties and chemical bonding. However, the sequence of ' $h$ ' values for the four fluids in TMMHP does not keep the same trend as they do in the SMMHP at all three orientations. Ethanol gained the highest value of ' $h$ ' whereas water gives the lowest. According to Newton's law of cooling, $h$ of a system with constant heat input and surface area gets the highest value for the smallest terminal temperature difference within the heat pipe and vice versa. This correlation can be authenticated by comparing Figure 16 and Figure 18 where water in TMMHP achieves the highest value of $h$. Consequently, at a small terminal temperature difference, the sharp decrease of pressure gradient leads to rapid condensation at the condenser port to increase the $h$ value. The calculated $h_{\text {eff }}$ values of all the fluids, based on the average temperature of the evaporator and condenser, for different inclinations are shown in Figure 20 (a-c). Effective heat transfer coefficients are different from the overall ones in case of all fluids. As it is noticed, in all three orientations, iso-propanol shows the highest $h_{\text {eff. However, the }}$ discrepancies between the two results may arise from the adiabatic section which may not be fully thermo-proof. Density is a thermophysical property of a fluid. Therefore, 
when the vapor becomes liquid at the condenser; the density of the fluid therein goes many folds high. However, the $h$ keeps no direct relationship with the density alone which reflects in both Figure 19 and Figure 20. Rather it was found that $h$ is compositely related with the fluid's density, pressure drop and heat input. This relationship can be expressed by $h=f(\rho(p(q)))$. Then the authors have developed the dimensionless correlations from this relationship presented later. In Figure 21(a-b), all the fluids' dimensionless heat transfer coefficients are shown including the water's $h / h_{\text {eff }}$ at single-metal micro heat pipe. The maximum value of ethanol is seen at $90^{\circ}$ at $6 \mathrm{~W}$ which is quite in match with its $h$ value (Fig.19 a-c). However, comparing the water's $h / h_{\text {eff }}$ value at TMMHP is twice as high as that of at SMMHP [6]. Such a result was from the two different thermal conductivities at the two ports of the TMMHP that initiate the quicker heat removal than that of the SMMHP, hence improves the $h$ so greatly. A comparison of thermal performances between the single-metal and two-metal micro heat pipe has been established in the Table 2.

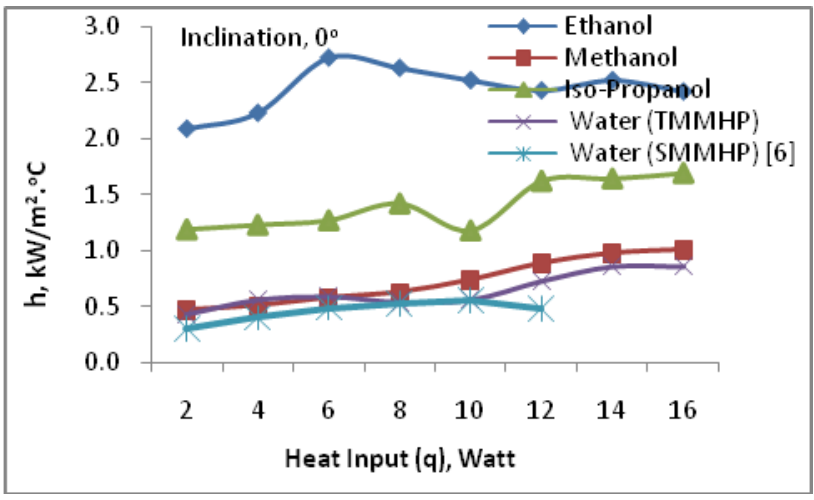

Figure 19 (a). Convec. coeff. of fluids vs. heat input inTMMHP

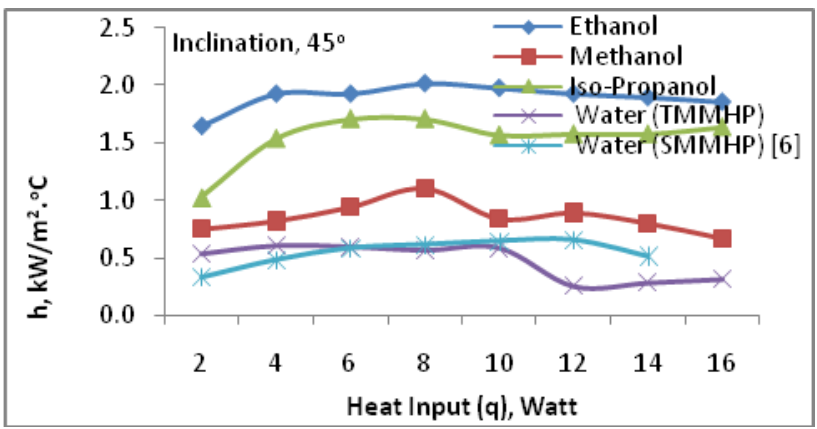

Figure 19 (b). Convec. coeff. of fluids vs. heat input in TMMHP

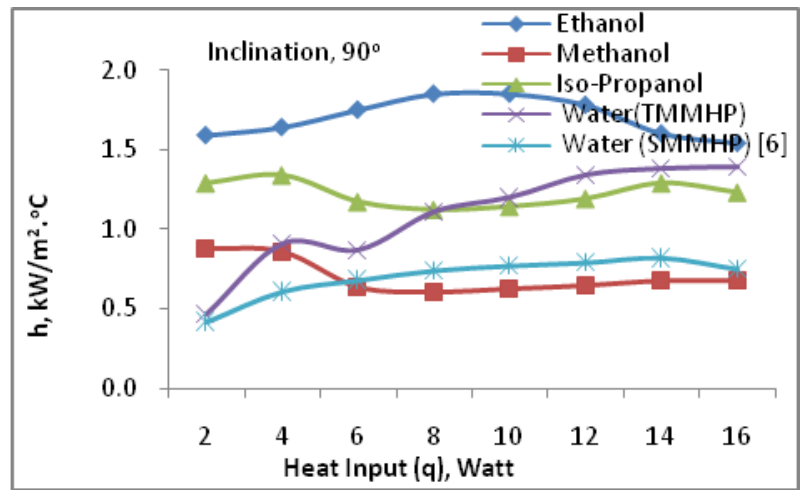

Figure 19 (c). Convec. coeff. of fluids vs. heat input in TMMHP

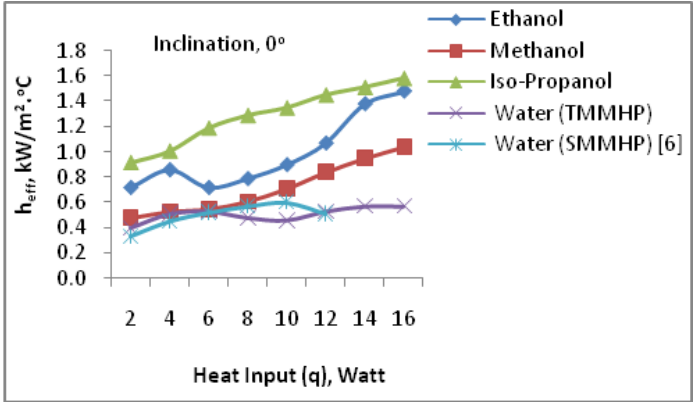

Figure 20 (a). Eff. convec.coeff.of fluids vs.heat inpu tinTMMHP

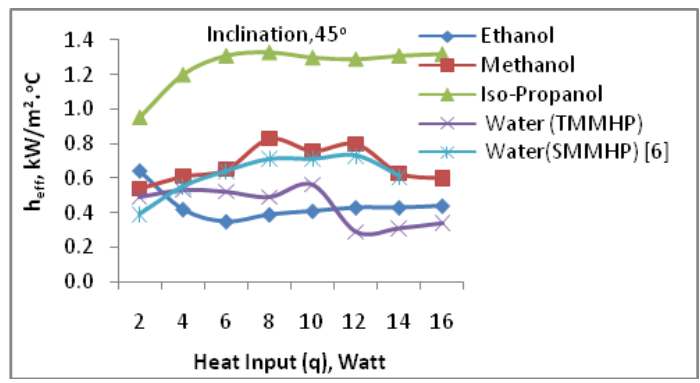

Figure 20 (b). Eff. convec. coeff. of fluids vs. heat input in TMMHP

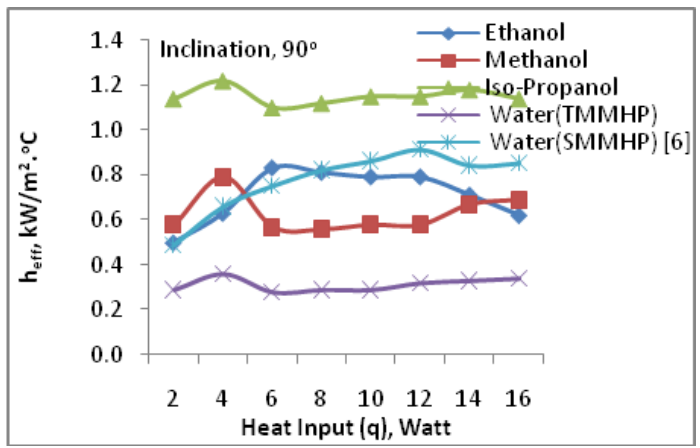

Figure 20 (c). Eff. convec. coeff. of fluids vs. heat input in TMMHP

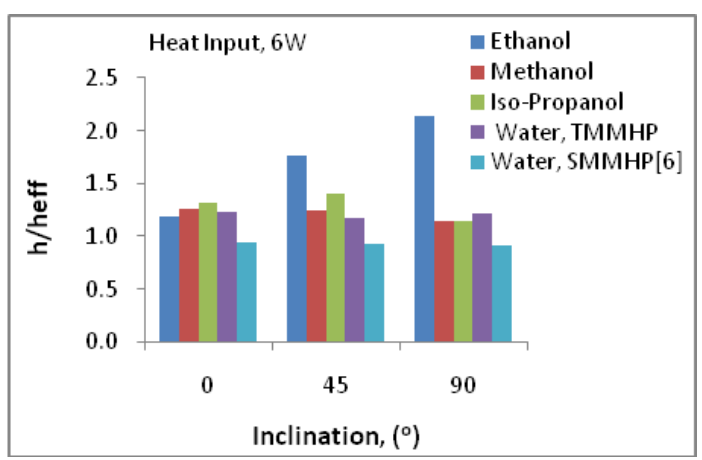

Figure 21(a). Comparison of $h / h_{e f}$ between TMMHP and SMMHP[6]

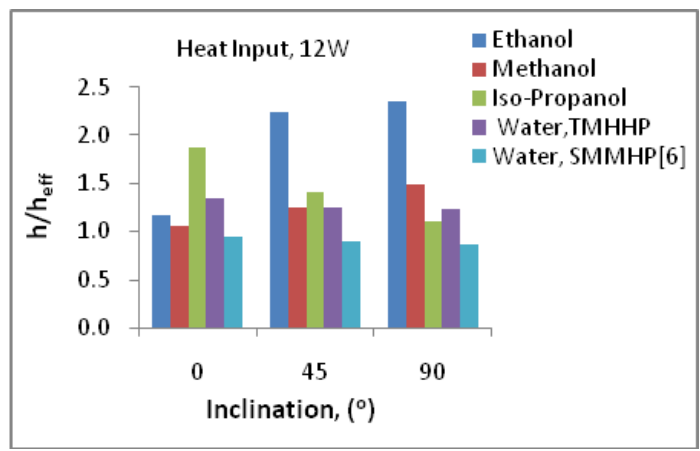

Figure 21(b). Comparison of $\mathrm{h} / \mathrm{h}_{\mathrm{ef}}$ between TMMHP and SMMHP [6] 


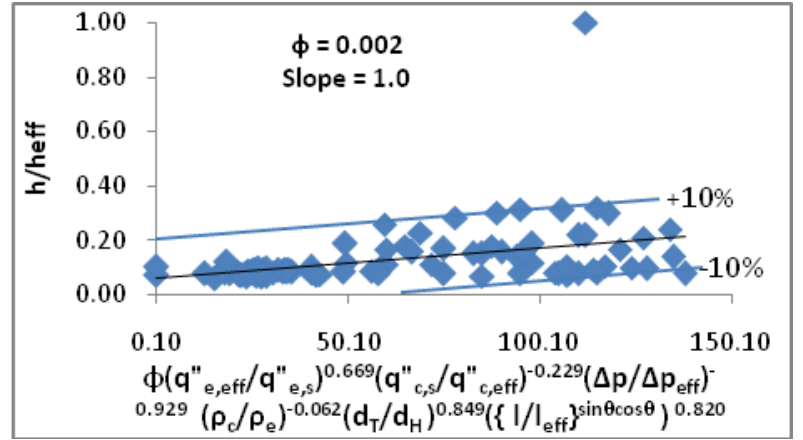

Figure 22. Graphical representation of the developed correlation of TMMHP

\section{Correlation}

A dimensionless correlation has been developed which correlates all the data collected in this study. It is mentioned earlier and shown in the graphs that a few common relations are found between heat transfer coefficient and other operating parameters. These common relations may be shown mathematically as $h=f(\rho(p(q)))$. In a dimensionless relation, the above function can be rewritten along with the calculated constants as follows.

$$
\frac{h}{h_{\text {eff }}}=0.002\left[\begin{array}{l}
\left(\frac{q^{\prime \prime}{ }_{e, e f f}}{q^{\prime \prime}{ }_{e, s}}\right)^{0.669}\left(\frac{q^{\prime \prime}{ }_{c, s}}{q^{\prime}{ }_{c, e f f}}\right)^{-0.229} \\
\times\left(\frac{\Delta P}{\Delta P_{e f f}}\right)^{-0.929}\left(\frac{\rho_{c}}{\rho_{e}}\right)^{-0.062} \\
\times\left(\frac{d_{T}}{d_{H}}\right)^{0.849}\left(\left\{\frac{l}{l_{\text {eff }}}\right\}^{\sin \theta \cos \theta}\right)^{0.820}
\end{array}\right]
$$

Graphical representation of all the correlated data is shown in Figure 22, and $98 \%$ of them are found to be within $\pm 10 \%$ range of the regression line.

\section{Conclusions}

From the study, the following conclusions can be drawn.

1. In SMMHP, the terminal temperature difference is very high comparing with that of in TMMHP. As a result, the $h$ of the working fluid produced by the SMMHP is much smaller than that of TMMHP.

2. Out of four working fluids, ethanol has been found to provide the highest $h$ at all three inclinations because of its low boiling point and density that enables quick completion of thermodynamic cycle.

3. It is proven that MHP made with the metals of variable thermal conductivity (i.e.TMMHP) of ascending order orientation, which initiates the super heater effect in the evaporator, indicates many folds better prospect of $h$ value than that of made with constant conductivity (SMMHP).

4. While an assumption of single phase flow in SMMHP works well at lower heat inputs, but at moderately high heat inputs it becomes a two-phase flow. However, the super heater effect at the evaporator in TMMHP eliminates that complexity of the two-phase and instantly turns into a single phase flow of vapor which was not possible in SMMHP $[6,7]$.

5. Even though the values of $h$ in TMMHP are many times higher than those of in SMMHP, the limitation of its value is obvious in both the heat pipes at a relatively higher heat input (i.e.12W).

6. The change of any specific physical property (i.e. density, specific gravity, viscosity) of a fluid singly cannot change the $h$ of that fluid in an MHP, rather it is a compound value developed functionally from both of its physical properties and state variables.

\section{Nomenclature}

$C_{p}, \quad$ specific heat at constant pressure, $\mathrm{kJ} / \mathrm{kg} .{ }^{\circ} \mathrm{C}$

$d_{H}, \quad$ hydraulic diameter of the heat pipe, $(m)$

$d_{T}$, profile height of the heat pipe, $(m)$

$h$ heat transfer coefficient for terminal temperature difference of the fluid, $\mathrm{kW} / \mathrm{m}^{2} .{ }^{0} \mathrm{C}$

$h_{\text {eff }}$ effective heat transfer coefficient for terminal average temperature difference of the fluid, $\mathrm{kW} / \mathrm{m}^{2} .{ }^{\circ} \mathrm{C}$

$l$, length of the heat pipe, $m$

$l_{\text {eff, }} \quad$ effective length of the heat pipe, $m$

$p$, pressure of the fluid, $\mathrm{Pa}\left(\mathrm{N} / \mathrm{m}^{2}\right)$

$q$, heat input, Watt

$\Delta p, \quad$ terminal pressure drop, $k P a$

$\Delta p_{\text {eff, }} \quad$ effective pressure drop at terminal average pressure, $\mathrm{kPa}$

$q^{\prime \prime}, \quad$ heat flux, $k W / m^{2}$

$q^{\prime \prime}{ }_{e, e f f}$ effective heat flux through the evaporator shell by conduction, $\mathrm{kW} / \mathrm{m}^{2}$

$q^{\prime \prime}{ }_{e, s}$, heat flux at the evaporator surface supplied by heater, $\mathrm{kW} / \mathrm{m}^{2}$

$q^{\prime \prime}{ }_{c, s}$, dissipated heat flux from the condenser surface by convection cooling, $\mathrm{kW} / \mathrm{m}^{2}$

$q^{\prime \prime}{ }_{c, e f f}$, effective heat flux dissipated through the condenser shell by conduction, $\mathrm{kW} / \mathrm{m}^{2}$

$T_{1}-T_{5}$, temperatures of the fluids in the micro heat pipe, ${ }^{0} \mathrm{C}$

$\rho$, density of the fluid, $\mathrm{kg} / \mathrm{m}^{3}$

$\rho_{c}, \quad$ density of the fluid at the condenser, $\mathrm{kg} / \mathrm{m}^{3}$

$\rho_{e}, \quad$ density of the fluid at the evaporator, $\mathrm{kg} / \mathrm{m}^{3}$

$\varphi, \quad$ dimensionless correlation constant

$\theta, \quad$ angle of inclination, degree $\left(^{\circ}\right)$

\section{Acknowledgement}

The authors gratefully acknowledge the total financial along with other necessary supports in conducting this research provided by the Islamic University of Technology (IUT), OIC, Bangladesh. The experiments were conducted in IUT labs.

\section{References}

[1] G. P. Peterson, "An Introduction to Heat Pipes-Modeling, testing and applications", John Wiley \& Sons, Inc., 1994. 
[2] G. M. Grover, T. P. Cotter and G. F. Erickson, "Structures of Very High Thermal Conductance", Journal of Applied Physics, 35(6): 1990-1991, 1964.

[3] P. D. Dunn and D. A. Reay, "Heat pipes", $3^{\text {rd }}$ Edition, Publisher: Robert Maxwell, Chapter 1-5, 1982.

[4] T. N. Sreenivasa, S. N. Sridhara and G. Pundarika, "Working fluid inventory in miniature heat pipe", Proceedings of the International Conference on Mechanical Engineering (ICME'05), Dhaka, Bangladesh, 2005.

[5] M. A. R. Akhanda, S.L.Mahmood and Ashik Ahmed, "An experimental investigation of an air-cooled miniature heat pipe (MHP) using different working fluids at different fill ratios", Proceedings of the $3^{\text {rd }}$ BSME-ASME International Conference on Thermal Engineering, Dhaka, Bangladesh, Paper No. BA 175, 2006.

[6] S. L. Mahmood, "Experimental Investigation on Micro Heat Pipes of Different Cross-sections having same Hydraulic Diameter", MS Thesis, Islamic University of Technology, OIC, Bangladesh, September 2007.

[7] A. S. Annamalai and V. Ramalingam, "Experimental investigation and computational fluid dynamics analysis of an air cooled condenser heat pipe", THERMAL SCIENCE, 15(3): 759-772, 2011.

[8] KMN S. Iqbal, "Thermal performances of two-metal (Cu-Ag) micro heat pipe (TMMHP)", Ph.D. Thesis (In progress), Islamic University of Technology, OIC, Bangladesh, October 2014 (Expected).

[9] KMN S. Iqbal and M. A. R. Akhanda, "Study of Two-metal (Cu$\mathrm{Ag}$ ) Micro Heat Pipe of Triangular Cross Section Using Different
Working Fluids of Low Boiling Point", SYLWAN, 158(6): 229248, 2014.

[10] S. H. Moon, "Improving Thermal Performance of Miniature Heat Pipe for Notebook PC Cooling", Microelectronics Reliability, 42(1):135-140, January 2002.

[11] B. R. Babin, G. P. Peterson, and D.Wu, "Steady-state Modeling and Testing of a Micro Heat Pipe," J. Heat Transfer, Vol. 112, 595-601, 1990.

[12] S. W. Chi, "Heat Pipe Theory and Practice,"McGraw-Hill, NY, U.S.A., 1976

[13] J. Longtin, B. F. Badran, and M. Gerner, "A One-dimensional Model of a Micro Heat Pipe during Steady-state Operation," J. Heat Transfer, Vol. 116, 709-715, 1994.

[14] L. W. Swanson and G. P. Peterson, "The Interfacial Thermodynamics of the Capillary Structures in Micro Heat Pipes," J. Heat Transfer, Vol.17, pp. 195-201, 1995.

[15] D. Wu and G. P., Peterson, "Investigation of the Transient Characteristics of a Micro Heat Pipe," J. Thermophysics, Vol. 5, 129-134, 1991.

[16] M. Le Berre, G. Pandraud, P. Morfouli, and M. Lallemand," The performance of micro heat pipes measured by integrated sensors". Journal of Micromechanics and Microengineering, 16:1047-1050, 2006.

[17] http://www.academia.edu/2787351/Thermal_performance_of_scre en_mesh_wick_heat_pipes_using_water-based_copper_nanofluids, Last visited on June 02,2014

[18] http://www.nanoscalereslett.com/content/7/1/322, Last visited on June 02, 2014. 